\title{
Helicobacter pylori Induces Gene Expression in Human Gastric Cells Identified by mRNA Differential Display
}

\author{
Lei Wong, Min-Yong Lue, C. Allen Chang, * Yuh-Ling Lin, and Err-Cheng Chan ${ }^{1}$
}

School of Medical Technology, Chang Gung College of Medicine and Technology, Taoyuan, Taiwan; and *Institute of Biological Science and Technology, National Chiao Tung University, Hsinchu, Taiwan

Received October 7, 1996

\begin{abstract}
Changes in gene expression patterns in gastric cells infected with Helicobacter pylori were characterized by means of mRNA differential display. Total RNA preparations were extracted from the H. pylori infected gastric cells and paired non-infected cells, and were probed with candidate clones identified after screening up to 6,000 mRNA species. Among them, four clones, 04G-1, 04G-2, 01G-1, and Cppa-2 show significant expression in the infected cells by Northern blot analysis, and they are 199 bp, 196 bp, 228 bp, and 276 bp in length, respectively. Database search revealed that nucleotide sequences of these clones share very low identity with any known sequence. These results indicate that $H$. pylori can significantly affect gene expression in gastric cells. Furthermore, mRNA differential display can be used in pathogenesis studies to identify new genes in gastric cells in response to insults such as H. pylori. (๑) 1996 Academic Press, Inc.
\end{abstract}

Helicobacter pylori infection is strongly associated with chronic gastritis $(1,2)$. However, peptic ulcer disease and gastric carcinoma occur in only a subset of individuals infected chronically with $H$. pylori $(3,4)$. Therefore, both bacterial and host factors are presumed to contribute to this differential response. In regard to bacterial factors, the success of $H$. pylori as a gastric pathogen is dependent on virulence factors such as those that allow $H$. pylori to survive in the hostile environment of the gastric lumen, including spiral shape and motility (5), adaptive enzymes and proteins (6-9), ability to adhere to gastric mucosal cells and mucus (10). Additional factors such as those that lead to disruption of the gastric mucosal barrier, including toxins $(11,12)$, mediators of inflammation (13), and contribute of gastric acid (14), are considered as pathogenic mechanisms of $H$. pylori.

In contrast, little is known regarding host factors in the $H$. pylori infection, particularly the changes in gene expression in the infected gastric cells. Comparisons of gene expression in pathological changes that arise in diseases such as peptic ulcers and even cancer provide the underlying information we need to analyze the biological processes induced by $H$. pylori infection (15). The aim of this study is to elucidate the molecular basis for gastric cells pathogenesis, and first it is necessary to isolated genes which are differentially expressed. Technique of differential display has recently been described to investigate differentially expressed mRNAs $(16,17)$. In the present report, $H$. pylori lysate was used as the stimulus, and we described a group of novel genes whose expression was significantly increased in the $H$. pylori stimulated gastric adenocarcinoma cells by the method of differential display. We also determined the nucleotide sequences of these cDNA fragments and compared homologies with those deposited in the DNA data base.

\footnotetext{
${ }^{1}$ Corresponding address: School of Medical Technology, Chang Gung College of Medicine and Technology, 259 Wen-Hua 1st Road, Kweishan, Taoyuan, Taiwan, ROC. Fax:886-3-3288741.
} 


\section{MATERIALS AND METHODS}

Bacterial strains and cultivation. The vacuolating toxin positive strain of Helicobacter pylori from ulcer patients were kindly given by Dr. N. Lee of Chang Gung memorial hospital, Taiwan. The bacteria were cultured on chocolate agar plates at $37^{\circ} \mathrm{C}$ in a microaerophilic atmosphere of $10 \% \mathrm{CO}_{2}$ in air and $99 \%$ humidity for three to four days. $H$. pylori appeared as curved-shaped rod under microscopy, and was examined by urease tests.

Preparation of $H$. pylori lysate. The $H$. pylori cells grown on agar plates were washed out with phosphate buffer saline (PBS, pH 7.2). The suspension of bacterial cells were disrupted by sonication (Heat-System Model XL 200, $\mathrm{NY}$ ) in ice bath at $35 \%$ pulse with $30 \mathrm{sec}$ intervals for $5 \mathrm{~min}$. The solution was centrifuged at $15,000 \times \mathrm{g}$ for 10 min at $4^{\circ} \mathrm{C}$. The supernatant was used as lysate for assay. Protein concentration was determined by Bradford method with a Bio-Rad protein assay kit according the manual instruction.

Cell culture. Human gastric adenocarcinoma cell line (AGS) was a gift from National Defense Medical Center, Taiwan. AGS cells were maintained and cultured as a monolayer in $50-\mathrm{cm}^{2}$ tissue culture flasks with RPMI1640 medium containing $10 \%$ fetal bovine serum, $100 \mu \mathrm{g} / \mathrm{ml}$ penicillin, and $100 \mu \mathrm{g} / \mathrm{ml}$ streptomycin. Cell culture was grown in an atmosphere of $5 \% \mathrm{CO}_{2}$ at $37^{\circ} \mathrm{C}$. Numbers of cells were counted after trypsinization by a Neubauer hemocytometer (VWR, Scientific Corp. Philadelphia, PA). Before isolation of RNA, the cells were divided into two groups, one was stimulated with $1.5 \mathrm{mg} / \mathrm{ml} \mathrm{H}$. pylori lysate for $4 \mathrm{~h}$, and the other one without adding $H$. pylori lysate was used as the normal cells.

Differential display of mRNA from H. pylori-infected and normal cells. Differential display of mRNA was performed as previously described with minor modification $(16,17)$. DNA-free RNA from the gastric cells was prepared by treatment with RNase-free DNaseI (Gibco BRL). Total RNA was isolated by TRIzol reagent-chloroform (Gibco BRL) extraction (18). After isopropanol precipitation, DNA-free total RNA $(0.1 \mu \mathrm{g})$ was reverse transcribed in 1X MMLV buffer which contained $2 \mu \mathrm{M}$ of either $\mathrm{T}_{11} \mathrm{~A}, \mathrm{~T}_{11} \mathrm{G}$ or $\mathrm{T}_{11} \mathrm{C}$ as the $3^{\prime}$-primer oligonucleotide, $10 \mathrm{mM}$ DTT, and 250 $\mu \mathrm{M}$ each of dGTP, dATP, dTTp, and dCTP. After the solution was heated at $70^{\circ} \mathrm{C}$ for $10 \mathrm{~min}$ and cooled to $42^{\circ} \mathrm{C}$, 200 units MMLV Superscript-II (Gibco BRL) was added for $50 \mathrm{~min}$ and then at $70^{\circ} \mathrm{C}$ for $15 \mathrm{~min}$. Polymerase chain reaction (PCR) was performed by adding 0.1 volume of reverse transcription reaction mixture in $1 \mathrm{X}$ PCR buffer which contained $2.5 \mu \mathrm{M}$ each of dNTP, $5 \mu \mathrm{C}_{\mathrm{i}}{ }^{35} \mathrm{~S}$-dATP, $0.2 \mu \mathrm{M}$ of the respective $\mathrm{T}_{11} \mathrm{~N}$ oligonucleotide, $0.2 \mu \mathrm{M}$ specific multiple arbitrary 10-mer oligonucleotide sets (Genosys Biotechnologies Co.), and 0.8 units Taq DNA polymerase (Promega Inc.). PCR reaction was performed in the Rapidcycler (Idaho Technology Inc.) at $94^{\circ} \mathrm{C}$ for $30 \mathrm{sec}$ and 40 cycles at $94^{\circ} \mathrm{C}$ for $2 \mathrm{sec}, 40^{\circ} \mathrm{C}$ for $40 \mathrm{sec}, 72^{\circ} \mathrm{C}$ for $30 \mathrm{sec}$ and followed by $72^{\circ} \mathrm{C}$ for $5 \mathrm{~min}$. Loading buffer was added to each PCR product solution and the samples electrophoresed on $6 \%$ acrylamide DNA sequencing gels under denaturing conditions. The gel was transferred onto $3 \mathrm{MM}$ paper and dried at $80^{\circ} \mathrm{C}$ for $45 \mathrm{~min}$, and exposed to Kodak XAR-5 film (Eastman Kodak) for $16 \mathrm{~h}$.

Reamplification of PCR products and Northern blot analysis. PCR fragments that were differentially expressed between the $H$. pylori infected and non-infected cells were cut out of the $3 \mathrm{MM}$ paper, phenol-chloroform extracted, and ethanol precipitated. PCR was repeated by using the same set of primers and conditions used in the first amplification reaction for differential display. The reamplified PCR products were separated on a $3 \%$ agarose gel, visualized by ethidium bromide staining, and eluted for using as a probe for Northern blot analysis or subcloning. For Northern blot, total cytoplasmic RNA $(10 \mu \mathrm{g})$ obtained from normal and $H$. pylori infected cells were separated on formaldehyde-denaturing $1 \%$ agarose gels and transferred to nylon membranes (Schleicher and Schuell). After UV crosslinking, blots were prehybridized at $40^{\circ} \mathrm{C}$ in $1 \times \mathrm{SSC}, 1 \% \mathrm{SDS}, 1 \times$ Denhardt's solution, $200 \mu \mathrm{g} / \mathrm{ml}$ salmon sperm DNA, $20 \mathrm{mM}$ Tris for $4 \mathrm{~h}$. Hybridization was continued at $40^{\circ} \mathrm{C}$ overnight in the presence of $1 \times 10^{6} \mathrm{cpm} /$ $\mathrm{ml}$ of random prime ${ }^{32} \mathrm{P}$-labelled probe. Following a wash at room temperature $2 \times \mathrm{SSC} / 0.1 \%$ SDS, blots were washed at $65^{\circ} \mathrm{C}$ for $20 \mathrm{~min}$ with $1 \times \mathrm{SSC} / 0.1 \%$ SDS. The washed membrane was autoradiographed for about $6 \mathrm{~h}$. The blots were stripped and reprobed with a ${ }^{32} \mathrm{P}$-labeled human glyceraldehyde-3-phosphate (GAPDH) gene probe.

Cloning and sequencing. Those samples showing significant changes by Northern blot analysis were subcloned into the pGEM-T vector with the TA cloning system from Promega. After the subcloned inserts were isolated and confirmed by Northern blot analysis, DNA sequencing was performed directly from the TA cloning vector using Sequenase version 2.0 kit (US Biochemical). T7 and SP6 promoter primers were used to locate the cloned insert. DNA sequences were analyzed by the FASTA search program of GCG package and were screened for homology against the GenBank/EMBL database sequences.

\section{RESULTS}

\section{Differential Display}

The expression of mRNA in H. pylori lysate stimulated AGS cells and paired normal cells were analyzed using combinations of forty 10 -mers and three $\mathrm{T}_{11} \mathrm{~N}$ primers. Each primer combination displayed 30 - 50 bands, allowing approximately 6,000 different mRNA species 


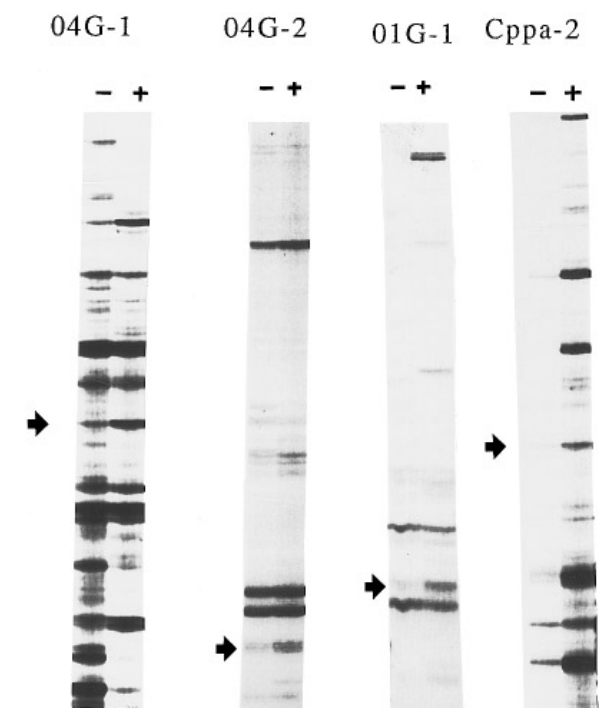

FIG. 1. Autoradiogram of differential mRNA display of candidate clones. Candidate cDNA fragments showing altered expresssion by differential mRNA display are marked by arrows and selected for subcloning. Lane + indicates cDNA fragments from normal AGS cells and lane - indicates $H$. pylori lysate stimulated AGS cells.

to be screened in this study. As shown in Fig. 1, arrow heads indicate that clones exhibited differences in their expression between normal and the $H$. pylori stimulated cells. These changes were confirmed by repeating the PCR and differential display procedures. We also use intact $H$. pylori as an infectious agent, the results showed that the differentiation of gene expression in the host cells was not so significant as compared with $H$. pylori lysate as the stimulus.

\section{Northern Blot Analysis}

When the isolated clones from the display gel were reamplified by PCR, some of the clones exhibited multiple bands different molecular size on agarose gel. Sixteen bands were eluted and subcloned into pGEM-T vector, and the clones were used as probes for Northern blot analysis. By Northern blot analysis using total RNA extracted from normal and $\mathrm{H}$. pylori stimulated cells , four clones (04G-1, 04G-2, 01G-1, Cppa-2) were found to be significant changes. As shown in Fig. 2, mRNAs for clone 01G-1 (6.5 kb, $4.4 \mathrm{~kb}$ and $2.5 \mathrm{~kb})$, clone 04G$1(5 \mathrm{~kb})$, clone 04G-2 (1.6 kb), and clone Cppa-2 (0.7 kb) were present in H. pylori stimulated cells but not in normal cells.

\section{Sequence}

The nucleotide sequences of clones 04G-1, 04G-2, 01G-1, and Cppa-2 are showed in Fig. 3. All these clones have variant polyadenylation signals. Searching of GenBank/EMBL databases revealed that these clones do not share any homology to previously known sequences.

\section{DISCUSSION}

Little is known about the choice of which genes are expressed in gastric cells in response to $H$. pylori insult. Studying the altered gene expression in the infected host cells can understand the regulatory mechanism that control pathological changes. $H$. pylori resides at the surface of gastric cells would lyse sometime after death, and the bacterial intracellular materials might 


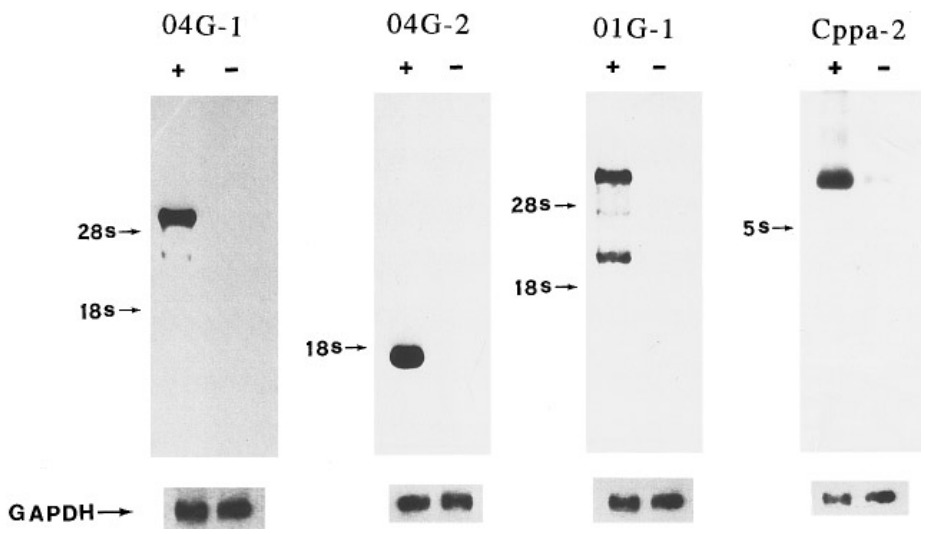

FIG. 2. Northern blot analysis using ${ }^{32} \mathrm{P}$-dATP labeled cDNA probes derived from reamplification of clones 04G1, 04G-2, 01G-1, and Cppa-2. The same blots were reprobed with GADPH cDNA as a loading control. Each lane represents $10 \mu \mathrm{g}$ of total cytoplasmic RNA isolated from normal or infected cells.

also influence the gastric cells. Therefore, we used the sonicated $H$. pylori lysate as the stimulus to represent the effect of total virulence factors on the host's gene expression. In this study, four genes are identified to be differentially expressed between $H$. pylori stimulated AGS cells and normal cells. We used recently developed differential display method to identify these

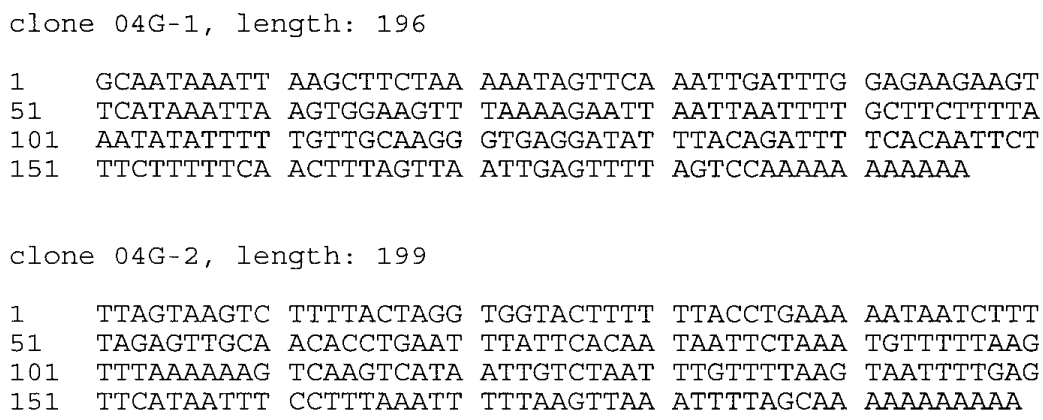

1 TTTGGCTGCC AAATTTTATA GATGTATCCT GAGTAGGGCA GGGCACGTGA 51 AACCCTGTCT GAATCTGCCG GGACCACCCG TAAGGCTAAA TACTAACAGA 101 CACCGATAGT GAACTAGTAC GTGAGGAAAG GTGAAAAGAA CCCCGAGAGG

151 AGTGAAATAG ATTCTGAAAC CATTTACTTA CAAGTAGTCA GAGCACGTTA 201 AAgTGTGATG GCGTACATCT TGCAgTATGg GCCGGCGAGT TATGTTAATA 251 ATCAAGGTTA AGCAGAAAAA AAAAAA

FIG. 3. Nucleotide sequence of clones 04G-1, 04G-2, 01G-1, and Cppa-2. All contain a poly(A) tail. 
genes (16). Those cDNA fragments do not share nucleotide homology with any known gene. The lack of homology for these clones with known sequences does not eliminate the possibility that they may be homologous to known proteins or protein families, since non-coding $3^{\prime}$ region of mRNA species show great species to species variation. Further work to clone the full length cDNAs of these genes are needed to clarify the identify of nucleotide sequence and to study their function as the pathogenic factors in gastric diseases. Although we do not know the role of expression of host cellular genes in the pathogenesis of gastric diseases associated with $H$. pylori infection, we speculate that this event is involved in the inflammatory response, which is an important factor of gastritis, ulcers, and presumably, gastric cancer. Gene expression stimulated by $H$. pylori might also initiate oncogenic transformation as a long-term effect.

Because the different bacterial pathogens share some common virulence factors and also possess unique pathogenic factors, responses of host cells to bacterial insults on the gene expression some are specific and some are non-specific for the invaded bacterium. At this moment, we can not make a conclusion whether or not those novel genes were specifically induced for $H$. pylori lysate, and we would not reject the assumption that those genes may be also highly induced by some other pathogenic bacteria. However, the success of $H$. pylori but not almost other pathogenic bacteria residing in stomach makes gene induction by $H$. pylori lysate have an unique and specific pathogenesis meaning.

Northern blots detected three distinct transcripts for clone $01 \mathrm{G}-1$ in the H. pylori lysate stimulated cells but not in normal ones. Several possibilities could contribute explain the occurrence of multiple transcripts, including alternative utilization of polyadenylation sites, alternative splicing of the message, or presence of extended $5^{\prime}$ untranslated region. The availability of full length cDNAs of these clones and the future availability of large amounts of $H$. pylori infected gastric mucosa samples will allow studies to determine if these novel genes or their coding proteins are related to the pathogenesis of peptic ulcers or even the development of the gastric cancer.

\section{ACKNOWLEDGMENT}

This research is supported by a grant "NSC-86-2314-B-182-046" from the National Science Council, Republic of China.

\section{REFERENCES}

1. Cover, T., and Blaser, M. (1995) ASM News 61, 21-26.

2. Telford, J. L., Covacci, A., Ghiara, P., Montecucco C., and Rappuoli, R. (1994) TIBTECH 12, $420-426$.

3. Dooley, C. P., Cohen, H., Fitzgibbons, P. L., Bauer, M., Appleman, M. D., Perez-Perez, G. I., and Blaser, M. J. (1989) N. Engl. J. Med. 321, 1562-1566.

4. Nomura, A., Stemmermann, G. N., Chyou, P. H., Perez-Perez, G. I., and Blaser, M. J. (1994) Ann. Intern. Med. 120, 977-981.

5. Eaton, K. A., Morgan, D. R., and Krakowka, S. (1989) Infect. Immun. 57, 1119-1124.

6. Dunn, B. E., Campbell, G. P., Perez-Perez, G. I., and Blaser, M. J. (1990) J. Biol. Chem. 265, 9464-9469.

7. Hazell, S. L., Evans, D. J., and Graham, D. Y. (1991) J. Gen. Microbiol. 137, 57-61.

8. Vargas, M., Lee, A., and Fox, J. G. (1991) Infect. Immun. 59, 706-712.

9. Hu, L. T., and Mobley, H. L. T. (1990) Infect. Immun. 58, 992-997.

10. Segal, E. D., Falkow, S., and Tompkins, L. S. (1996) 93, 1259-1264.

11. Cover, T. L., Halter, S. A., and Blaser, M. J. (1992) Hum. Pathol. 23, 1004-1010.

12. Cover, T. L., and Blaser, M. J. (1992) J. Biol. Chem. 267, 10570-10575.

13. Fukuda, T., Kimura, S., and Arakawa, T. (1990) J. Clin. Gastroenterol. 12, (suppl I), S131.

14. Levi, S., Beardshall, K., and Swift, I. (1989) Br. Med. J. 299, 1504-1509.

15. Lewin, B. (1990) Cell 61, 743-750.

16. Liang, P., and Pardee, A. B. (1992) Science 257, 967-971.

17. Liang, P., Averboukh, L., and Pardee, A. B. (1993) Nucl. Acids Res. 21, 3269-3275.

18. Chomczynski, P. (1993) Biotech. 15, 532-536. 